\title{
Factors associated with glycemic control among adult patients with type 2 diabetes mellitus: a cross-sectional survey in Ethiopia
}

\author{
Tefera Kassahun', Tesfahun Eshetie ${ }^{2}$ and Hailay Gesesew $3,4^{*}$
}

\begin{abstract}
Background: Even though the prevalence of type 2 diabetes mellitus is swelling rapidly in Ethiopia, data regarding glycemic control, a key strategy for marked reduction of diabetes mellitus complications, is scant. We have assessed the status of glycemic control and its contributing factors among adult patients with type 2 diabetes mellitus.

Methods: This was a facility based cross-sectional survey of 325 adults with type 2 diabetes mellitus attending in Jimma University Teaching Hospital, South west Ethiopia. Data from all the patients were collected between February and April 2014. Glycemic level was assessed by using fasting blood glucose level, and 'poor glycemic control'was defined when fasting blood glucose level was above $130 \mathrm{mg} / \mathrm{dL}(7 \mathrm{~mm} / \mathrm{L})$. Analysis included both descriptive and inferential statistics, and SPSS version 20.0 was used for all analysis.

Results: 309 respondents were included in the survey. More than two-third (70.9\%) of the patients had poor blood glycemic control. Patients who were illiterate $(A O R=3.46,95 \% \mathrm{Cl} 1.01-11.91)$ and farmer $(A O R=2.47,95 \% \mathrm{Cl}$ 1.13-5.39) had high odds of poor glycemic control. In addition, taking combination of insulin and oral medication ( $A O R=4.59,95 \% \mathrm{Cl} 1.05-20.14$ ) and poor medication adherence (AOR $=5.0895 \% \mathrm{Cl}$ 2.02-12.79) associated statistically with poor glycemic control.

Conclusion: Majority of patients had poor glycemic control. Patients with low level of education, being employed, on combinations of insulin and oral medication, and lower adherence to their medication were likely to have poor glycemic control. Education and awareness creation could be a cross cutting intervention for the significant factors.
\end{abstract}

Keywords: Glycemic control, Fast blood glucose, Cross-sectional, Type 2 diabetic mellitus, Ethiopia

\section{Background}

Diabetes mellitus (DM) [1] has been ravaging millions of people from all over the world. Globally, diabetes has killed 4.6 million people in 2013 alone [2]. More than $77 \%$ of morbidity [3] and $88 \%$ of mortality [4] due to DM occur in low- and middle-income countries. In Ethiopia, the prevalence of diabetes was $3.5 \%$ in 2011 [5]. Type 2 diabetes mellitus (T2DM) is the most common form of DM, accounting for more than $90 \%$ of cases [2]. Control of diabetes is more than just taking medicine; other aspects of self-management such as self-monitoring of

\footnotetext{
*Correspondence: hailushepi@gmail.com

${ }^{3}$ Department of Epidemiology, College of Health Sciences, Jimma

University, Jimma, Ethiopia

Full list of author information is available at the end of the article
}

blood glucose, dietary restrictions, regular foot care and ophthalmic examination have all been shown to markedly reduce the incidence and progression of diabetes complications [2]. Previous studies have reported that suboptimal glycemic control could cost diabetes patients more care requirement, associated health-care costs, and loom the complications $[6,7]$.

The prevalence of poor glycemic control is paramount. A study done in Malaysia [8], 2015 showed that $72 \%$ of patients had poor glycemic control, and two third of DM patients in Ethiopia [9] also had poor control. Previous studies assured that poor glycemic control correlated with enlarged risk of visual impairment [10], enlarged risk of kidney failure [11], and enlarged risk of cardiovascular disease [12]. In addition, the possible 
reasons included lack of awareness, time constraint, lack of adequate human power, poor adherence, and most importantly lack of appropriate guidelines and diabetes education for both care givers and patients $[9,13]$. Therefore, it is easy to understand that adequate glycemic control among T2DM patients prevents short-term complications, decrease the risk of long-term complications, and decrease health care resource use and costs [14-16]. This figure indicted the need to give an attention for glycemic control. The Healthy People 2020 aimed a $10 \%$ reduction in the proportion of DM patients with poor glycemic control as a target [17].

But despite the swift growth of prevalence of T2DM in Ethiopia, data regarding glycemic control, the key strategy for marked reduction of acute and chronic complications of DM, is scant. Such data are noteworthy for the overall diabetic health care delivery services. We have assessed the status of glycemic control and its contributing factors among adult patients with T2DM.

\section{Methods}

\section{Study design, settings and participants}

A facility based cross-sectional study was carried out in diabetic clinic at Jimma University Teaching Hospital (JUTH), Southwest Ethiopia from February 14 to April 9, 2014. The hospital serves the rural, urban and semiurban areas. Drug Administration and Control Authority of Ethiopia Contents [18], a guideline similar with International Diabetes Federation clinical guideline [3] were followed for diagnosis and classification of DM. The study was conducted among T2DM adult patients ( $\geq 18$ years) who were on active follow up for at least four visits. The required sample size was calculated via OpenEpi software using single population proportion calculation formula using the following assumptions: $58.2 \%$ prevalence rate of poor glycemic control [19], $95 \%$ confidence level, $5 \%$ margin of error and $10 \%$ non-response rate. Considering a correction formula, the total calculated sample yielded 325. Using sampling frame of DM records, simple random sampling technique was used to recruit the study participants (Fig. 1).

\section{Variables of the study and measurement}

Glycemic level was the response variable that was coded as poor or good. Poor glycemic control was operationally defined if fasting blood glucose (FBG) level was above $130 \mathrm{mg} / \mathrm{dl}$. Patients FBG reading for at least 4 months were recorded and computed the mean blood glucose level [20]. The explanatory variables included: sociodemographic and economic data (age, sex, level of education, marital status, occupation, income, ethnicity and religion), history of smoking, history of alcohol consumption, family history of DM, medication adherence,

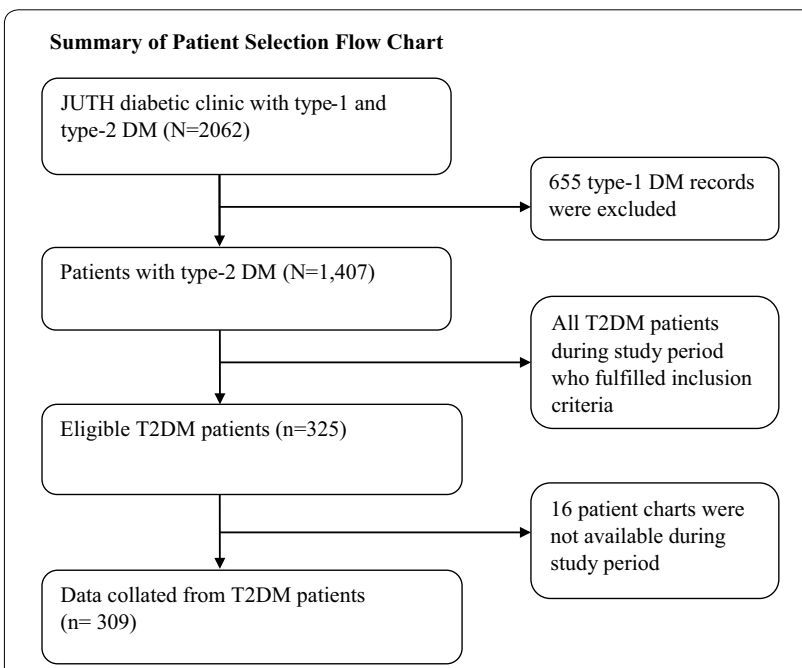

Fig. 1 Summary of flowchart record selection, 2014

duration of therapy, body mass index (BMI) and number of diabetic medication.

Level of education was classified as illiterate (could not read and write their local language-'Afan Oromo' or 'Amharic'), literate (could read and write but received no formal education), primary (received education up to class eight), secondary (received education class 9-12), and college/university (joined college or university). History of smoking and history of alcohol consumption has been assessed as during lifetime. Family history of DM was measured if any family member (mother or father) had DM. Morisky adherence score [21], eight-item yes/ no questionnaire, was used to assess the self-reported measures of adherence to medications. For all questions, responses were coded 1 if patients responded 'yes' otherwise 0 if not, except one question that was coded reverse. The total score of adherence was classified into low adherence if the score was $>2$, medium adherence if between 1 and 2, and high adherence if 0 .

Demographic and clinical characteristics were assessed via face-to-face interview and the average glycemic levels were reviewed from their chart. To ensure quality of data, the tool was developed in English, translated to local language (Amharic and Afan-Oromo) and back translated into English to check its consistency.

\section{Statistical analysis}

Descriptive statistics included mean, median, standard deviations, and range values for continuous data; percentage and frequency tables for categorical data. Bivariate logistic regression analysis was conducted to see the existence of crude association and select candidate variables (with P value below 0.25 were considered) 
to multivariable logistic regression. We checked multicollinearity among selected independent variables via variance inflation factor (VIF) and none was found. $P$ value $\leq 0.05$ was considered as a cut point for statistical significance in the final model. Fitness of goodness of the final model was checked by Hosmer and Lemeshow and was found fit. The Data was summarized using odds ratio (OR) and $95 \%$ confidence interval. The analysis was done in Statistical Package for the Social Sciences (SPSS) 20 version software [22].

\section{Ethical considerations}

Informed consent was obtained from study participants before the commencement of each interview, and no personal identification was registered. There was no any financial compensation or provision for the study participants. Permission was obtained from JUSH and the study was approved by institutional review board (IRB) of college of health sciences at Jimma University, Southwest Ethiopia.

\section{Results \\ Socio-demographic and clinical characteristics of respondents}

Three hundred and twenty-five DM patients were considered eligible, whereof 16 were excluded since their chart were not available (Fig. 1). In total, 309 patients included in the analysis making $95 \%$ response rate. Table 1 shows demographic and economic characteristics of the respondents. Males were over-represented (61.8\%) and almost two-fifth (36.9\%) of the respondents represented the age group 51-60 years. Nearly half (46.6\%) of the respondents followed Muslim religion and four out of five $(81.2 \%)$ respondents were married. Two fifth $(36.2 \%)$ respondents attained grades (1-8), and $30.4 \%$ of respondents were farmers.

Table 2 shows clinical characteristics of the respondents. Mean BMI of the respondents was $24.4( \pm 4.39) \mathrm{kg} /$ $\mathrm{m}^{2}$, and $33 \%$ of the respondents had overweight. Great majority of the respondents had not access for self-monitoring blood glucose (SMBG). About half of the respondents had not get social support, and one fourth (24.6\%) of the respondents had family history of DM. The prevalence of smoking and alcohol, respectively, was 3 and $5 \%$. DM patients were followed for an average of $7.2( \pm 5.8)$ years with a minimum of 4 months and a maximum of 40 years. Diabetic neuropathy was the most common DM complication accounting for $41.5 \%$. Regarding diabetic medications, $63.1 \%$ of respondents were taking oral medication only followed by insulin $(25.6 \%)$. The respondents took a mean of $3.66( \pm 1.60)$ medications ranged between 1 and 7 medications.

\section{Glycemic control level and its contributing factors among T2DM patients}

Poor glycemic control was seen in 219 (70.9\%) respondents. Age, sex, education, occupation, BMI, anti-diabetics, number of medications and adherence to medication were the candidate variables for multiple logistic regression. The following factors were statistically significant in bivariate logistic analysis: being illiterate, being achieved grades 1-8, being employed, being farmer, being under weight, taking combinations of insulin and oral medication, taking 2-4 drugs and $>4$ drugs, medium medication adherence and low medication adherence. In multiple logistic regression, statistically significant difference was found in poor glycemic control to education, occupation, anti-diabetics and level of medication adherence.

Table 3 presents the multiple logistic regression analysis with demographic and clinical characteristics, and poor glycemic control. The association of poor glycemic control among illiterate respondents was three times $(\mathrm{AOR}=3.46$, $95 \%$ CI 1.01-11.92) greater than among those who were in college/university. The relative probability of poor glycemic control among farmers was higher than $(\mathrm{AOR}=2.47$, $95 \%$ CI 1.14-5.39) unemployed ones. Compared to respondents who took oral medication, respondents who took combinations of insulin and oral medication were five times $(\mathrm{AOR}=4.59,95 \% \mathrm{CI} 1.05-20.14)$ more likely to have poor glycemic control. On the other hand, the odds of poor glycemic control among patients who had medium and low adherence to their medication were three $(\mathrm{AOR}=3.49,95 \% \mathrm{CI} 1.72-7.09)$ and five times (AOR $=5.08,95 \%$ CI 2.02-12.79) more than patients who had high adherence to their medication respectively.

\section{Discussion}

The main goal of diabetes management is to ensure optimal glycemic control. We have assessed the magnitude of poor glycemic control and associated factors among T2DM patients. Results of this study showed that nearly three fourth of patients with T2DM had poor glycemic control. This result was comparable to those obtained in an earlier study that reported $65 \%$ [23] and $81.9 \%$ [24] of respondents had poor glycemic control. This significant proportion of poor glycemic control in the country underpins the need to work more on self-management strategies of DM patients. The current finding is far higher than from developed countries such as $12.9 \%$ in United States [7]. This variation could be due to knowledge difference of respondents between developing and developed countries, absence of uniform guidelines in assessing glycemic control for physicians to set the score cutoff, and the presence health insurance and the difference in health insurance coverage and access to primary care $[7,25,26]$. 
Table 1 Socio-demographic characteristics of T2DM patients on follow up at JUTH, 2014

\begin{tabular}{|c|c|c|}
\hline $\begin{array}{l}\text { Socio-demographic } \\
\text { characteristics }(n=309)\end{array}$ & Categories & n (\%) \\
\hline \multirow[t]{2}{*}{ Sex } & Male & $189(61.8)$ \\
\hline & Female & $120(38.2)$ \\
\hline \multirow[t]{5}{*}{ Age } & $18-32$ & $5(1.6)$ \\
\hline & $33-41$ & $30(9.7)$ \\
\hline & $42-50$ & $72(23.3)$ \\
\hline & $51-60$ & $114(36.9)$ \\
\hline & $\geq 61$ & $88(28.5)$ \\
\hline \multirow[t]{4}{*}{ Marital status } & Married & $251(81.2)$ \\
\hline & Single & $9(2.9)$ \\
\hline & Divorce & $12(3.9)$ \\
\hline & Widow/er & $37(12.0)$ \\
\hline \multirow[t]{7}{*}{ Ethnicity } & Oromo & $170(55.1)$ \\
\hline & Amhara & $78(25.2)$ \\
\hline & Keficho & $21(6.8)$ \\
\hline & Gurage & $10(3.2)$ \\
\hline & Dawero & $8(2.6)$ \\
\hline & Yem & $8(2.6)$ \\
\hline & Other $^{\mathrm{a}}$ & $14(4.5)$ \\
\hline \multirow[t]{5}{*}{ Educational level } & Illiterate & $87(28.2)$ \\
\hline & Read \& write & $22(7.1)$ \\
\hline & $1-8$ & $112(36.2)$ \\
\hline & $9-12$ & $44(14.3)$ \\
\hline & College/University & $44(14.2)$ \\
\hline \multirow[t]{4}{*}{ Religion of respondents } & Muslim & $144(46.6)$ \\
\hline & Orthodox & $138(44.7)$ \\
\hline & Protestant & $23(7.4)$ \\
\hline & Others $^{b}$ & $4(1.3)$ \\
\hline \multirow[t]{5}{*}{ Occupation } & Farmer & $94(30.4)$ \\
\hline & No job & $78(25.2)$ \\
\hline & Employed & $72(23.3)$ \\
\hline & Merchant & $29(9.4)$ \\
\hline & Daily labor & $36(11.7)$ \\
\hline
\end{tabular}

a Tigre, Wolayita

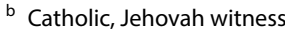

Significant difference of poor glycemic control was observed among illiterates than college/university graduates. Consistent with this, studies from Jordan [27] and China [28] reported the correlation of lower level of education and poor glycemic control. This could indicate illiterate patients had low diabetes knowledge, low self-management behaviors, lower self-efficacy and lower continuity of care. Thus, we are recommending investment on getting rid of illiteracy as it has a significant impact on the reduction of diabetic morbidity and mortality [29, 30]. Poor glycemic control appeared to be greater among farmers compared to unemployed
Table 2 Clinical characteristics of T2DM patients on follow up at JUTH, 2014

\begin{tabular}{|c|c|c|}
\hline Clinical characteristics $(n=309)$ & Category & n (\%) \\
\hline \multirow[t]{4}{*}{ Body mass index } & Under weight & $17(5.5)$ \\
\hline & Normal weight & $161(52.1)$ \\
\hline & Over weight & $102(33.0)$ \\
\hline & Obese & $29(9.4)$ \\
\hline \multirow[t]{2}{*}{ Family/social support } & Yes & $175(56.6)$ \\
\hline & No & $134(43.4)$ \\
\hline \multirow[t]{2}{*}{ Family history } & Yes & $76(24.6)$ \\
\hline & No & $233(75.4)$ \\
\hline \multirow[t]{3}{*}{ Habit of smoking } & Smoker & $9(2.9)$ \\
\hline & Non-smoker & $287(92.9)$ \\
\hline & Ex-smoker & $13(4.2)$ \\
\hline \multirow[t]{2}{*}{ Alcohol drinking } & Non-drinker & $293(94.8)$ \\
\hline & Drinker & $16(5.2)$ \\
\hline \multirow{2}{*}{$\begin{array}{l}\text { Access for self-monitoring blood } \\
\text { glucose }\end{array}$} & Yes & $30(9.7)$ \\
\hline & No & $279(90.3)$ \\
\hline \multirow[t]{3}{*}{ Duration of treatment } & $<5$ & $145(46.9)$ \\
\hline & $5-10$ & $105(33.9)$ \\
\hline & $>10$ & $59(19.2)$ \\
\hline \multirow[t]{3}{*}{ Anti-diabetics } & Insulin & $79(25.6)$ \\
\hline & Oral medication & $195(63.1)$ \\
\hline & Insulin \& oral medication & $35(11.3)$ \\
\hline \multirow[t]{4}{*}{ Diabetic complication $(n=352)$} & Neuropathy & $146(41.5)$ \\
\hline & Nephropathy & $56(15.9)$ \\
\hline & Retinopathy & $94(26.7)$ \\
\hline & Cardiac complications & $56(15.9)$ \\
\hline \multirow[t]{3}{*}{ No. of medications } & $<2$ drugs & $115(37.2)$ \\
\hline & $2-4$ drugs & $135(43.7)$ \\
\hline & $>4$ drugs & $59(19.1)$ \\
\hline
\end{tabular}

respondents. This, however, might be due to allocating less time for self-management. Majority of the farmers in this study were also illiterate compared to unemployed respondents implying that farmers might have poor awareness of self-care of DM.

It was also likely that the difference in glycemic control might result from differences in anti-diabetic treatment. Compared to respondents on oral medication, respondents who were on combinations of insulin and oral medication were five times more likely to have poor glycemic control. This association was corroborated by study done in Malaysia [31]. The poor control among patients receiving a combination of insulin and oral anti-diabetic drugs shows that multi therapy might challenge satisfactory glycemic control. There was a strong inverse association between adherence level and poor glycemic control as supported by the previous studies [32]. Showing very poor outcomes among respondents who fail to comply with the prescribed clinical regimen is not surprising 
Table 3 Factors independently associated with poor glycemic level among T2DM patients JUTH, 2014

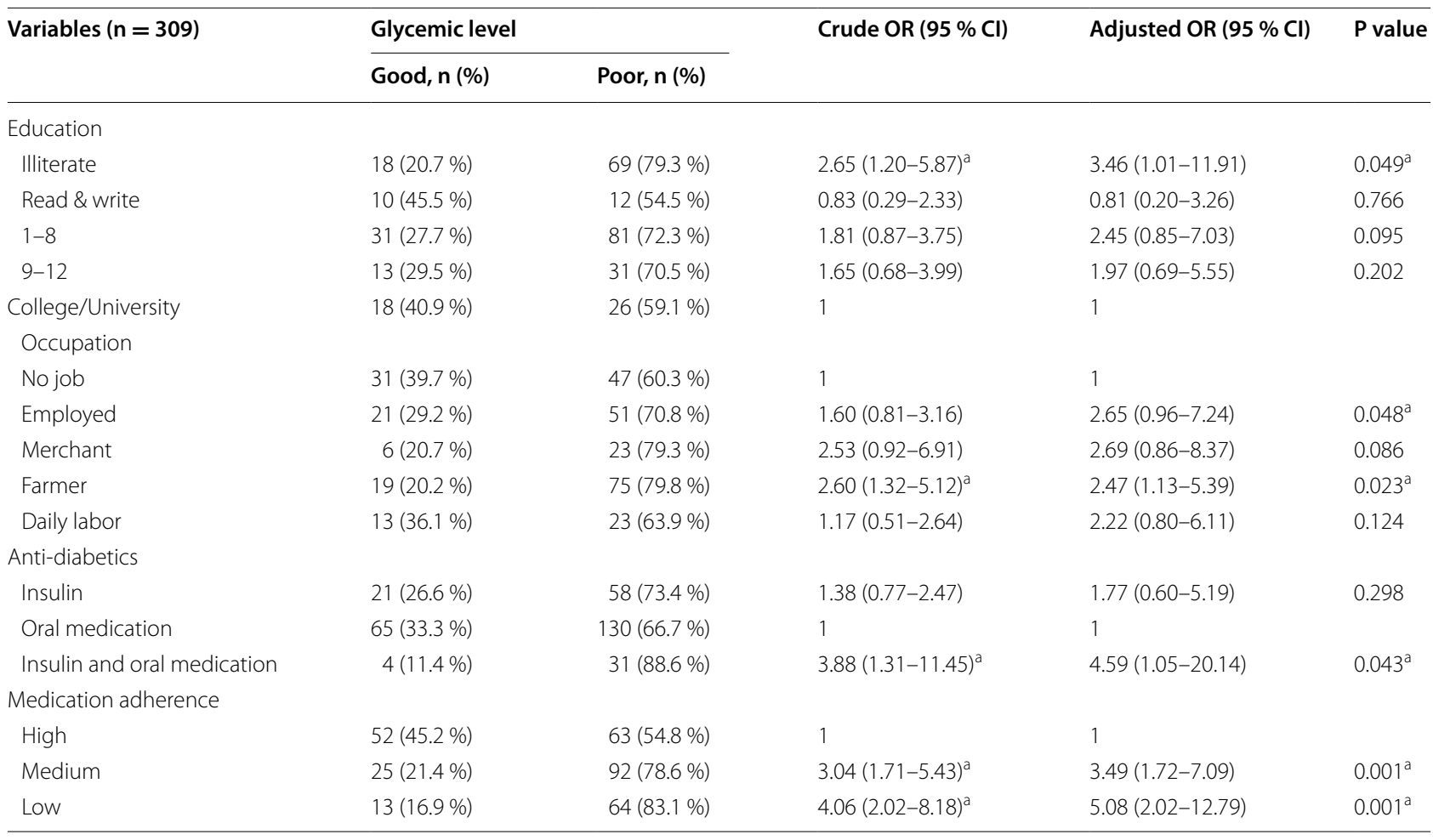

a Statistically significant at $\mathrm{P}$ value $<0.05$

[33]. Accordingly, counseling and improving adherence rather than changing medication or altering the dose has been suggested [33]. It is plausible to have an endeavor to tackle non-adherence by designing strategies encompassing cost, health belief, dosing frequency, personality disorders and patient provider relationship.

Worth noting limitations should have noted in this study. The use of FBS over HbA1c my under estimate the prevalence of poor glycemic control even though FBS was found more reliable than HbA1c [34]. The institutional based nature of the study might not infer for other diabetic patients. The nature of cross-sectional study design does not show temporal relationship or causality. Recall bias might also be there during measuring selfreport of medication to adherence.

\section{Conclusion}

In summary, the findings from the current study agree in many points with the findings of previous publications. Significant number of DM patients did not achieve the recommended glucose level. This was affected by education, occupation, anti-diabetic treatment and adherence status of the patients. Education and awareness creation could be a cross cutting intervention for the significant factors. We recommend further population based research.

\section{Abbreviations}

BMI: body mass index; DM: diabetes mellitus; FBG: fasting blood glucose; HbA1c: glycosylated hemoglobin; IDFA: International Diabetes Federation Atlas; JUSH: Jimma University Specialized Hospital; OHA: oral hypoglycemic agent; SMBG: self-monitoring blood glucose; SDSCA: summary of diabetes self-care activities; T2DM: type-2 diabetes mellitus.

\section{Authors' contributions}

TK involved in designing of the study, data collection, data analysis, drafting and critically reviewing the manuscript. Likewise, TE and HG involved in designing of the study, analysis of the data and critically reviewing the manuscript. All authors read and approved the final manuscript.

\section{Author details}

${ }^{1}$ Dilchora Hospital, Dire Dawa, East Ethiopia. ${ }^{2}$ Department of Clinical Pharmacy, College of Health Sciences, Jimma University, Jimma, Ethiopia. ${ }^{3}$ Department of Epidemiology, College of Health Sciences, Jimma University, Jimma, Ethiopia. ${ }^{4}$ Discipline of Public Health, Faculty of Medicine, Nursing and Health Sciences, Flinders University, Adelaide, Australia.

\section{Acknowledgements}

The authors are grateful to the data collectors who gathered the data. This research was funded by Jimma University.

\section{Competing interests}

The authors declare that they have no competing interest. This research was funded by Jimma University. The funders had no role in study design, data collection and analysis, decision to publish, or preparation of the manuscript.

Received: 19 November 2015 Accepted: 31 January 2016

Published online: 09 February 2016 


\section{References}

1. Islam SM, Niessen LW, Seissler J, Ferrari U, Biswas T, Islam A, Lechner A. Diabetes knowledge and glycemic control among patients with type 2 diabetes in Bangladesh. SpringerPlus. 2015:4:284

2. Aschner P, Beck-Nielsen H, Bennett P, Boulton A, Colagiuri R. Diabetes and impaired glucose tolerance. 5th ed. Brussels: IDF Diabetes Atlas; 2012.

3. IDF. Diabetes and impaired glucose tolerance. 6th ed. Brussels: Diabetes Atlas; 2013.

4. Mathers CD, Loncar D. Projections of global mortality and burden of disease from 2002 to 2030. PLoS Med. 2006;3(11):e442.

5. Whiting DR, Guariguata L, Weil C, Shaw J. IDF diabetes atlas: global estimates of the prevalence of diabetes for 2011 and 2030. Diabetes Res Clin Pract. 2011;94(3):311-21.

6. Harris MI. Racial and ethnic differences in health care access and health outcomes for adults with type 2 diabetes. Diabet Care. 2001;24(3):454-9.

7. Ali MK, Bullard KM, Imperatore G, Barker L, Gregg EW. Characteristics associated with poor glycemic control among adults with self-reported diagnosed diabetes-National Health and Nutrition Examination Survey, United States, 2007-2010. MMWR Morb Mortal Wkly Rep. 2012;61(2):32-7.

8. Firouzi S, Barakatun-Nisak MY, Azmi KN. Nutritional status, glycemic control and its associated risk factors among a sample of type 2 diabetic individuals, a pilot study. J Res Med Sci. 2015;20(1):40-6.

9. Abebe SM, Berhane Y, Worku A, Alemu S, Mesfin N. Level of sustained glycemic control and associated factors among patients with diabetes mellitus in Ethiopia: a hospital-based cross-sectional study. Diabet Metab Synd Obes. 2015;8:65-71.

10. Colagiuri S, Lee CM, Wong TY, Balkau B, Shaw JE, Borch-Johnsen K. Glycemic thresholds for diabetes-specific retinopathy: implications for diagnostic criteria for diabetes. Diabet Care. 2011;34(1):145-50.

11. Lachin JM, Genuth S, Nathan DM, Zinman B, Rutledge BN. Effect of glycemic exposure on the risk of microvascular complications in the diabetes control and complications trial-revisited. Diabetes. 2008;57(4):995-1001

12. Selvin E, Marinopoulos S, Berkenblit G, Rami T, Brancati FL, Powe NR, Golden SH. Meta-analysis: glycosylated hemoglobin and cardiovascular disease in diabetes mellitus. Ann Intern Med. 2004;141(6):421-31.

13. Gudina EK, Amade ST, Tesfamichael FA, Ram R. Assessment of quality of care given to diabetic patients at Jimma University Specialized Hospital diabetes follow-up clinic, Jimma. Ethiopia. BMC Endocr Disord. 2011;11:19.

14. Fiallo-Scharer R. Eight-point glucose testing versus the continuous glucose monitoring system in evaluation of glycemic control in type 1 diabetes. J Clin Endocrinol Metab. 2005;90(6):3387-91.

15. JDRF. Randomized clinical trial to assess the efficacy of real-time continuous glucose monitoring in the management of type 1 diabetes: research design and methods. Diabet Technol Ther 2008; 10(4):310-21.

16. Tamborlane WV, Beck RW, Bode BW, Buckingham B, Chase HP, Clemons R, Fiallo-Scharer R, Fox LA, Gilliam LK, Hirsch IB, et al. Continuous glucose monitoring and intensive treatment of type 1 diabetes. New Engl J Med 2008;359(14):1464-76.

17. Healthy People 2020, 2015. http://www.healthypeople.gov/2020/topicsobjectives2020/objectiveslist.aspx?topicld $=8$.
18. DACA. Standard treatment guideline for primary hospitals. 2nd ed. Addis Ababa; 2010.

19. Wabe NT, Angamo MT, Hussein S. Medication adherence in diabetes mellitus and self management practices among type-2 diabetics in Ethiopia. NAm J Med Sci. 2011;3(9):418-23.

20. ADA. Standards of medical care in diabetes - 2013. Diabet Care 2013, 36(1): 11-66.

21. Morisky DE, Green LW, Levine DM. Concurrent and predictive validity of a self-reported measure of medication adherence. Med Care. 1986;24(1):67-74.

22. IBM Corp. Released 2011. IBM SPSS Statistics for Windows, Version 20.0. Armonk, NY: IBM Corp.

23. Gebrehiwot T, Jemal H, Dawit T. Non-adherence and Associated Factors among type 2 diabetic patients at Jimma University Specialized Hospital, Southwest Ethiopia. J Med Sci. 2013;13:578-84.

24. Hailu E, Mariam WH, Belachew T, Birhanu Z. Self-care practice and glycaemic control amongst adults with diabetes at the Jimma University Specialized Hospital in south-west Ethiopia: A cross-sectional study. Afr J Prim Health Care Fam Med. 2012;4(1):311-6.

25. Islam SM, Niessen LW, Seissler J, Ferrari U, Biswas T, Islam A, Lechner A Diabetes knowledge and glycemic control among patients with type 2 diabetes in Bangladesh. SpringerPlus. 2015:4:284.

26. Wee HL, Ho HK, Li SC. Public awareness of diabetes mellitus in Singapore. Singap Med J. 2002:43(3):128-34.

27. Al-Akour NA, Khader YS, Alaoui AM. Glycemic control and its determinants among patients with type 2 diabetes mellitus attending a teaching hospital. J Diabet Metab. 2011;2:129

28. Yin J, Yeung R, Luk A, Tutino G, Zhang Y, Kong A, Chung H, Wong R, Ozak $\mathrm{R}, \mathrm{Ma} \mathrm{R}$ et al. Gender, diabetes education, and psychosocial factors are associated with persistent poor glycemic control in patients with type 2 diabetes in the Joint Asia Diabetes Evaluation (JADE) program. J Diabet. 2015;8(1):109-19. doi:10.1111/1753-0407.12262

29. Gautam A, Bhatta DN, Aryal UR. Diabetes related health knowledge, attitude and practice among diabetic patients in Nepal. BMC Endocr Disord. 2015;15:25.

30. Rani PK, Raman R, Subramani S, Perumal G, Kumaramanickavel G, Sharma T. Knowledge of diabetes and diabetic retinopathy among rural populations in India, and the influence of knowledge of diabetic retinopathy on attitude and practice. Rural Remote Health. 2008;8(3):838

31. Huri HZ, Lim LP, Lim SK. Glycemic control and antidiabetic drugs in type 2 diabetes mellitus patients with renal complications. Drug Des Dev Ther. 2015:9:4355-71.

32. Khattab M, Khader YS, Al-Khawaldeh A, Ajlouni K. Factors associated with poor glycemic control among patients with type 2 diabetes. J Diabet Complicat. 2010;24(2):84-9.

33. Leichter S. Making outpatient care of diabetes more efficient: analyzing noncompliance. Clin Diabet. 2005;23:187-90.

34. Ghazanfari Z, Haghdoost AA, Alizadeh SM, Atapour J, Zolala F. A Comparison of $\mathrm{HbA1c}$ and Fasting Blood Sugar Tests in General Population. Int J Prev Med. 2010;1(3):187-94.

\section{Submit your next manuscript to BioMed Central and we will help you at every step:}

- We accept pre-submission inquiries

- Our selector tool helps you to find the most relevant journal

- We provide round the clock customer support

- Convenient online submission

- Thorough peer review

- Inclusion in PubMed and all major indexing services

- Maximum visibility for your research

Submit your manuscript at www.biomedcentral.com/submit
() Biomed Central 